\title{
Selective ion uptake in the initial phase and root surface potentials
}

\author{
J. H. Grobler
}

Department of Soil Science, University of Potchefstroom, Potchefstroom, Republic of South Africa

To understand the effect of changes in the soil solution on plant growth a knowledge of the ionic composition of the soil solution at the root surface is of the utmost importance. Ion uptake in different plant species is dependent on the influence exerted by the plant on the soil solution. Schuffelen \& Loosjes (1942) termed the biological processes by which plants obtain their nutrients from the soil solution the 'pump function'. The idea that salt absorption is an active process has thus been established for more than 30 years. The details of how respiratory energy is used to bring this about are still not clear and schemes linking the physical processes of diffusion and exchange to metabolism are under investigation.

The relation between the composition of the soil solution and the solid phase is fairly well understood. According to Schuffelen \& Bolt (1958) the cationic composition of the soil solution can more or less be characterized by the ionic saturation of the soil absorption complex and the moisture content of the soil. Schuffelen \& Koenigs (1962) further showed the importance of solubility products for the concentration of ions forming slightly soluble compounds.

In terms of the formula given by Schuffelen (1944), i.e. absorption $=\mathrm{f}$ (plant, environment, time), the ionic environment plays an important part. The working hypothesis of Schuffelen \& Loosjes (1942) considered cation absorption as a diffusion process. This implies that the absorption of cations depends on the activity of the ion in the medium, the $\mathrm{pH}$ of the medium and on the activity of the ions in the imaginary surface of the root. The application of the Langmuir adsorption isotherm introducing a correction for adsorption on the surface of the root (Schuffelen \& Loosjes, 1946) emphasizes the importance of the negative potential between the root and the solution. The recognition of the fact that an adsorption equilibrium, which is established very quickly, is followed by a slower absorption from the postulated adsorption layer greatly influenced the experimental approach to ion uptake in subsequent years.

Ions present in the soil solution near the root surface are subject to three processes which may occur successively or simultaneously. The ions first of all enter and pass through an apparent free space (AFS) of cell walls before they reach the centres of active uptake in cortex cells. In the apparent free space both cations and anions are adsorbed into external or internal root surfaces. Thirdly active or metabolic accumulation takes place. The question which has not yet been satisfactorily answered is whether the adsorption in the AFS has any bearing on the active accumulation phase. To answer this question one should find a model of ion uptake which accounts both for the negative electrical potential at the root surface (Lundegardt, 1940, 1945) and the specific adsorption of cations and anions in the initial uptake phase.

If the free space denotes a volume to which ions of the outside solution have free access by diffusion it can be considered an extension of the outside solution and its presence will not affect the relation between accumulation and the composition of the 
solution. Due to the presence of adsorption sites it is therefore more appropriate to think in terms of an apparent free space as originally defined by Briggs \& Robertson (1957).

That living roots adsorp cations is clearly demonstrated by the work of Epstein \& Leggett (1954). They showed that cations adsorbed could not be removed by water but could be exchanged by an isotope of the same ion. The adsorption of cations by living roots has been shown to be very specific (Fried et al., 1958). Petterson (1966) found that at low concentrations in the ambient solution a considerable fraction of the sulfate is bound by adsorption exchange in the AFS.

Active accumulation of ions is now commonly described by a carrier model. The ion combines with the carrier forming a carrier-ion combination that must go through a metabolic step requiring energy, to bring the ion into the internal metabolic system of the plant. The kinetic equations resembles that of enzyme kinetics

$$
\mathrm{R}+\mathrm{M} \underset{\mathrm{K}-1}{\stackrel{\mathrm{K}_{1}}{\underset{\mathrm{T}}{\longrightarrow}}} \mathrm{MR} \text { and } \mathrm{MR}_{\stackrel{\mathrm{K}_{2}}{\longrightarrow}}^{\longrightarrow} \mathrm{M}(\mathrm{acc})+\mathrm{R}^{1}
$$

In the reaction series $K_{2}$ is the rate limiting step. In the active metabolic process specific carriers are operating for each ionic species or group of ions.

The starting point for active accumulation is the reversible adsorptive combination of the ion $\mathbf{M}$ with the carrier $\mathbf{R}$. The adsorption of the ion onto the carrier site shows the same specifity as the metabolic accumulation process. Evidence that the adsorption phenomenon is linked to metabolic activity is gained from the ability of noncompetitive inhibitors to affect the amount of adsorption (Laties, 1959; Barber \& Russell, 1961).

Fried \& Broeshart (1967) pointed out that the simple formation of carrier-ion combinations does not take into account the necessity that, in order to maintain electrical neutrality in the external solution, either equivalent numbers of cations and anions must be taken up by the plant or for each cation or anion taken up by the plant it has to give off to the solution an ion with the same number of charges of the same sign. This agrees with the fact that hydrogen is fully competitive with all of the cations according to Fried \& Noggle (1958) and Rains et al. (1964). Waisel et al. (1966) suggests that these relations are governed by the physical properties of the ions involved, e.g. by their rate of migration across the outher surface of the cells, by their affinity for attachment sites, but most all by their relative concentration at the attachment sites of the temperature dependent mechanism.

The affinity for the attachment sites can be expressed by the stability constant $\mathrm{K}$ of the carrier-ion combination MR. This is related to the $\mathrm{Km}$ values for the various ionic species reviewed by Fried \& Broeshart (1967). The $\mathrm{Km}$ values listed by them are of the same magnitude as that of various metal chelates listed by Chabarek \& Martell (1959), ranging from $1^{-10}$ to $10^{-1}$ and less. Shemyakin et al. (1969) indicate that neutral macrocyclic depsides, depsipeptides and certain polyethers do form complexes with monovalent cations. The stability constants for $\mathrm{K}^{+}$and $\mathrm{Na}+$ enniatins are 9.8 and 2.9 , respectively, at the one extreme and 1.6 and 2.2 at the other extreme.

It has also been shown by various authors that plants exhibit two distinct carrier sites for the same ionic species at different concentrations. Organic liquids having very few co-ordinating groups have the property of step by step complex formation. Successive stabilities resulting from ter- and quadridentate ligands differ so greatly that the first is very much more stable than the second. Hence the first chelate is formed completely before formation of the second begins. 
Because of the basic properties of most ligands they are usually associated with hydrogen over a wide $\mathrm{pH}$ range. Therefore the formation of a metal chelate compound frequently involves a displacement of hydrogen ions from the ligand.

$$
\begin{aligned}
& \mathrm{M}+\mathrm{n}+\mathrm{HA} \longrightarrow \mathrm{MAn}^{\mathrm{n}}+\mathrm{H}^{+} \\
& \mathrm{M}+\mathrm{n}+\mathrm{H}_{\mathrm{m}} \mathrm{A} \longrightarrow \mathrm{MA}^{\mathrm{n}-\mathrm{m}}+\mathrm{mH}+
\end{aligned}
$$

Bürstrom (1963) indicates that growth inhibition by EDTA and homologous compounds is caused by competition with natural ligands in the cell. The ligands involved on roots may or may not be ionic as must be those of cation exchange. They need not be confined to the cell walls. Metal chelation in ion uptake by plant roots could easily explain the appearance of $\mathrm{H}+$ in the process. The release of a proton as a result of chelation is more likely than as a result of exchange because of the position of $\mathrm{H}$ in the lyotropic series (Wallace, 1962).

Its seems therefore feasible to postulate a diffusion of ions across the boundary of the apparent free space. The specific binding of ions to carrier substances (probably chelate formation), reduces the activity of the ion to practically zero. Such a position has been proposed by Kurella (1960). Such a model need not necessarily be at variance with the observed cation exchange properties of plant roots. It is possible that in the chelating action of plant roots carboxyl groups radiating from pores in the root epidermis may act as chelating agents. The cation can move within the pore by isotopic exchange in the same manner as was observed for metal chelates (Wallace, 1962). It is also evident that ionic specificity is only exhibited by living tissue so that what is exchangeable in dead roots may be specifically adsorbed in living roots. Lundegårdh $(1940,1955)$ regarded the protoplasmic surface of epidermal cells as consisting of a monolayer of oriented acided molecules, some of which are dissociated giving rise to exchangeable hydrogen ions in the protoplasmic surface. He interpreted root potentials as being a measure of the rates of hydrogen ion activities in the adsorbed monolayer and the solution.

In the light of specific adsorption sites in the AFS the observed negative root potentials can no longer be explained by a simple Donnan system with contrained anions separated by a membrane from the external solution. Furthermore active uptake should then be proportional to the higher concentration in the adsorption phase. Evidence is still lacking to show that there is a relation between the concentration of the inner solution and active uptake.

Various investigators have tried to elucidate the nature of electric potentials in living cells. A diffusion potential may be obtained when the salt solution diffuses into the root as was suggested by Hope \& Stevens (1952) and Hope (1953). If the mobility of the cation is greater than that of the anion a positive potential gradient can be expected which will tend to zero at equilibrium with the outside solution. Diffusion as driving force can only operate along a concentration gradient. Teorell (1935) discussed the characteristics of a system in which there is a constant concentration gradient across a permeable membrane, resulting in a continuous steady diffusion of one electrolyte across the membrane. An electrical potential arises because of the different mobilities of the ions of this activity diffusing electrolyte. This potential constitutes an energy factor and results in a Boltzman distribution of ions of any other passive electrolyte present in the system, until the concentration gradient just balances the electrical gradient. The steady state potential is a measure of the relative activities of ions of the passive electrolyte on two sides of the membrane. Thus if an organic acid is produced on the inside of the root boundary at as fast a rate as it diffuses into an infinitely large 
outside volume, a steady state diffusion potential will exist. Schematically such a system as given by Teorell (1935) is presented as follows:

outside : inside

$$
\begin{aligned}
& \mathrm{H}_{\mathrm{o}}^{+} \mathrm{A}_{\circ}^{-}: \mathrm{H}_{\mathrm{i}}^{+} \mathrm{A}_{\mathrm{i}}^{-} \\
& \mathrm{M}_{\mathrm{o}}^{+} \mathrm{B}_{\mathrm{o}}^{-}: \mathrm{M}_{\mathrm{i}}^{+} \mathrm{B}_{\mathrm{i}}^{-} \\
& \text {boundary }
\end{aligned}
$$

For such a two phase system the following equation holds:

$$
-\mathbf{E}=\frac{\mathrm{U}_{\mathrm{H}}-\mathrm{V}_{\mathrm{A}}}{\mathrm{U}_{\mathrm{H}}+\mathrm{V}_{\mathrm{A}}} \quad \frac{\mathbf{R T}}{2 \mathrm{~F}} \ln \frac{\mathrm{H}_{\mathrm{i}}^{+}+\mathrm{M}_{\mathrm{i}}^{+}}{\mathrm{H}_{\mathrm{o}}^{+}+\mathrm{M}_{\mathrm{o}}^{+}}
$$

Where $U_{H}$ and $V_{A}$ are mobilities of the cation and anion respectively of the actively diffusing electrolyte $\mathrm{HA}, \mathrm{E}$ is then determined by the ratios $\mathrm{U}_{\mathrm{H}} / \mathrm{V}_{\mathrm{A}}, \mathrm{H}_{\mathrm{i}}^{+} / \mathrm{H}_{\mathrm{o}}^{+}$and $\mathrm{H}_{\mathrm{i}}^{+} / \mathrm{M}_{\mathrm{o}}^{+}$. This model does not take into account specific adsorption phenomenon and was found unsatisfactory to explain potentials obtained in systems containing divalent ions and mixtures of monovalent and divalent cations (Grobler, 1959).

A steady state diffusion potential can be obtained over a boundary when the concentrations of ionic components are kept constant on both sides. Such a situation can develop when an organic acid is released in the AFS at the same rate as it diffuses into an infinitely larger outer volume and when the ions of a salt in the outer solution are diffusing into the AFS at the same rate as they are bound to carrier sites. The special form of the Goldman equation (Hodgin \& Katz, 1949) for such a situation gives the membrane potential when only monovalent ions are present in the system.

$$
-\mathrm{E}=\frac{\mathrm{RT}}{\mathrm{F}} \ln \frac{\Sigma\left(\mathrm{U}_{\mathrm{m}} \cdot \mathrm{M}+\right)_{\mathrm{i}}+\Sigma\left(\mathrm{V}_{\mathrm{A}} \cdot \mathrm{A}^{-}\right)_{\mathrm{o}}+\Sigma\left(\mathrm{V}_{\mathrm{B}} \cdot \mathrm{B}^{-}\right)_{\mathrm{o}}}{\Sigma\left(\mathrm{U}_{\mathrm{m}} \cdot \mathrm{M}+\right)_{\mathrm{o}}+\Sigma\left(\mathrm{V}_{\mathrm{A}} \cdot \mathrm{A}^{-}\right)_{\mathrm{i}}+\Sigma\left(\mathrm{V}_{\mathrm{B}} \cdot \mathrm{B}^{-}\right)_{\mathrm{i}}}
$$

When the integrated flux equations for divalent cations are added to the integrated equations a quadratic equation is obtained:

$$
\begin{aligned}
& \Sigma 2 \mathrm{U}_{\mathrm{tn}}+\mathrm{M}^{2+}+\Sigma \mathrm{uM}_{\mathrm{o}}^{+}+\Sigma \mathrm{vA}_{\mathrm{i}}=\frac{1}{\mathrm{~K}^{2}}\left(\Sigma \mathrm{uH}_{\mathrm{i}}^{+}+\Sigma 2 \mathrm{uM}_{\mathrm{i}}^{2+}+\Sigma \mathrm{vA}_{\mathrm{o}}^{-}\right)+ \\
& +\left(\Sigma \mathrm{uH}_{\mathrm{i}}^{+}+\Sigma \mathrm{vA}_{\mathrm{o}}^{-}-\Sigma \mathrm{vA}_{\mathrm{i}}^{-}-\Sigma \mathrm{uM}_{\mathrm{o}}^{+}\right)
\end{aligned}
$$

where $\mathrm{K}=\mathrm{e}-\mathrm{EF} / \mathbf{R T}$.

When we assume that the concentration of all cations other than hydrogen on the inside of the boundary is zero, the two equations can be used to calculate theoretical potentials.

In Fig. 1 and 2 theoretical potentials are compared with experimental potentials for roots of peas (Pisum sativa). The following assumptions with regard to mobilities were made:

1. $\mathrm{HA}$ inside $=10^{-3} \mathrm{~N}$

2. $\mathrm{pH}$ outside $=7$

3. $\mathrm{U}_{\mathrm{H}}=480 \mathrm{~V}_{\mathrm{A}}=48 \mathrm{U}_{\mathrm{K}}=60 \mathrm{U}_{\mathrm{Ca}}=96 \mathrm{U}_{\mathrm{Na}}=80 \mathrm{U}_{\mathrm{Mg}}=48 \mathrm{~V}_{\mathrm{Cl}}$

In a system containing only monovalent ions the maximum potential is determined by the ratio $U_{H}: V_{A}$, the middle portion of the curve is determined by $U_{H}: U_{K}$, while the potential in the concentrated range is determined by the ratio $U_{M}: U_{H}$. 

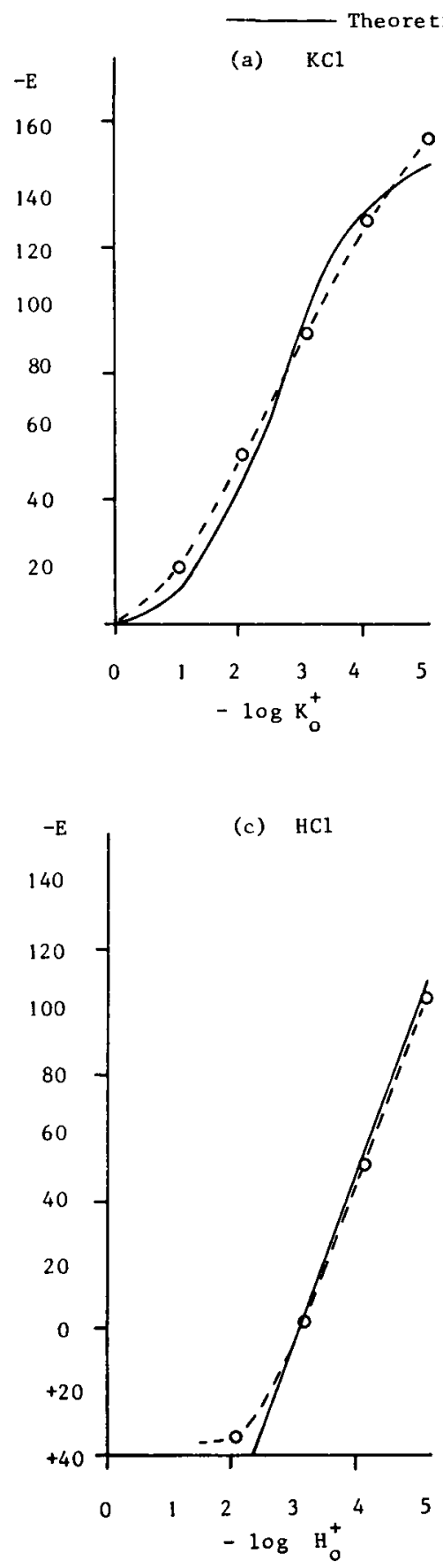

o- - - -o Experimental

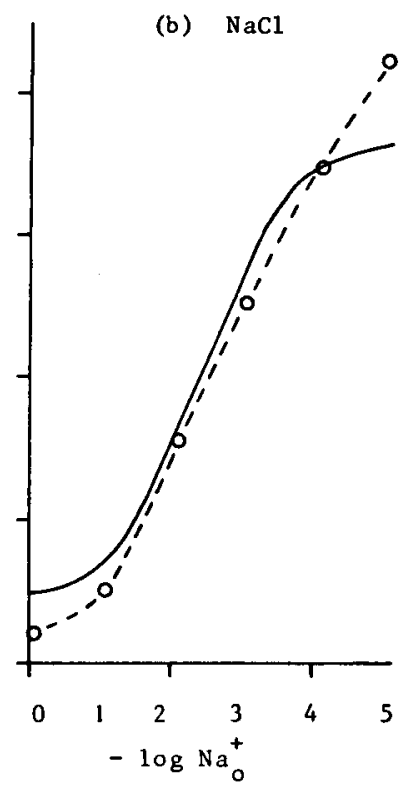

(d) $\mathrm{KCl}-\mathrm{NaCl}$

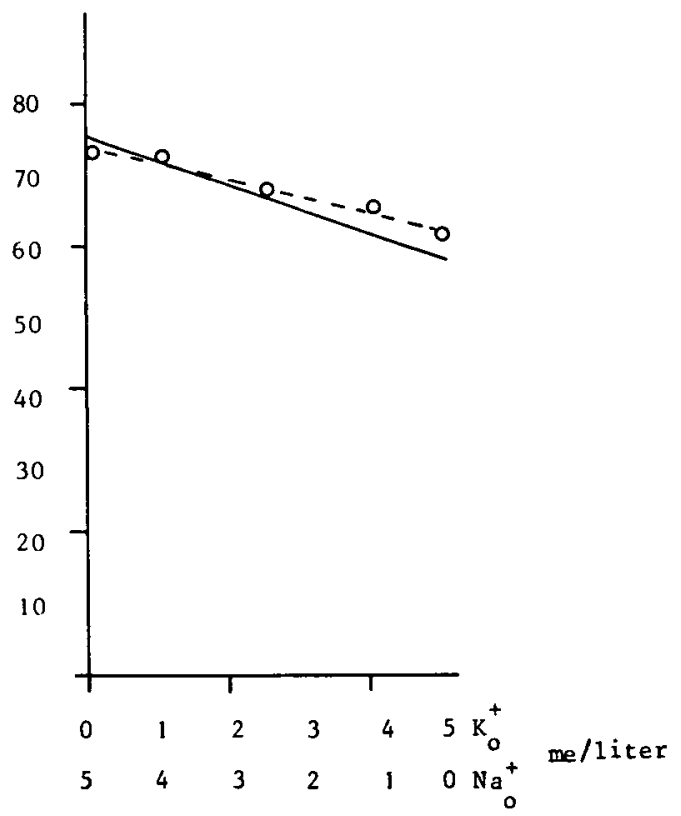

Fig. 1. Potentials in chloride solutions of monovalent cations. 
SELECTIVE ION UPTAKE IN THE INITIAL PHASE AND ROOT SURFACE POTENTIALS
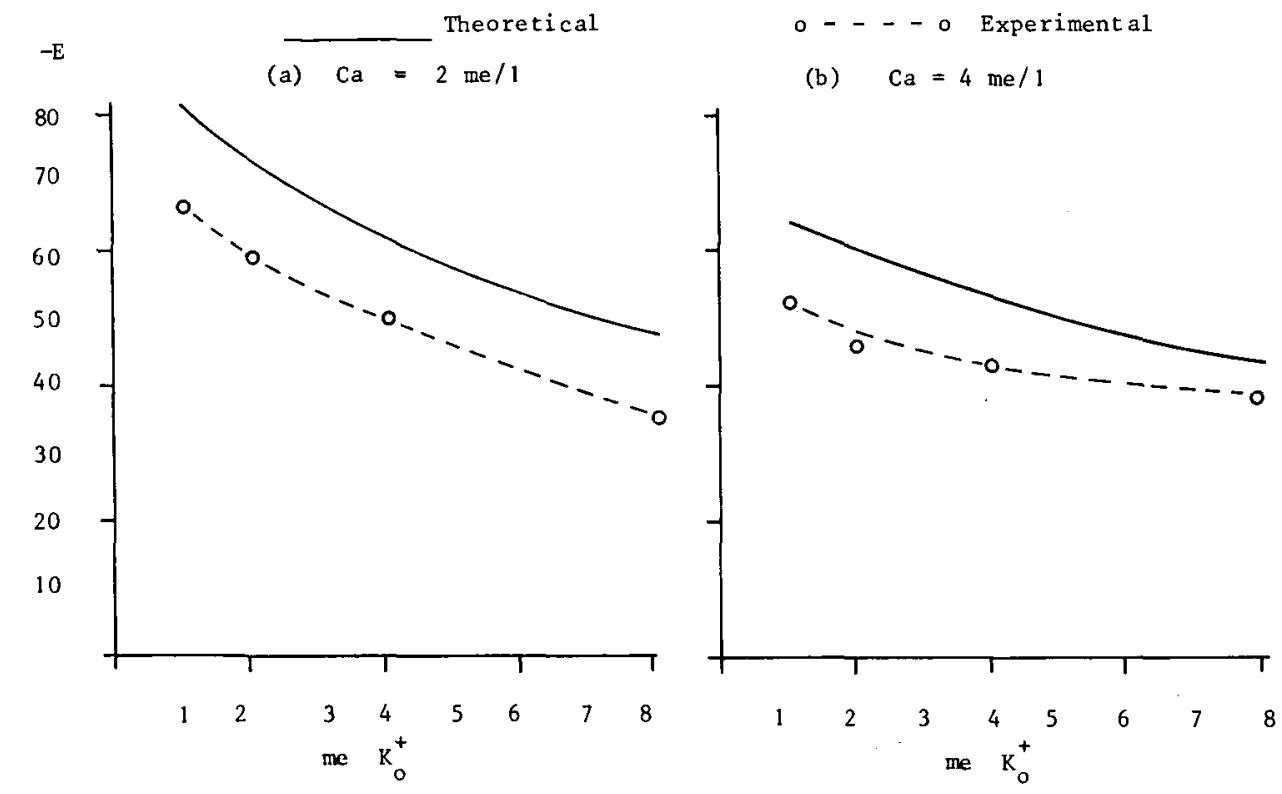

(a) $\mathrm{Mg}=2 \mathrm{me} / 1$.

(b) $\mathrm{Mg}=8 \mathrm{me} / 1$.
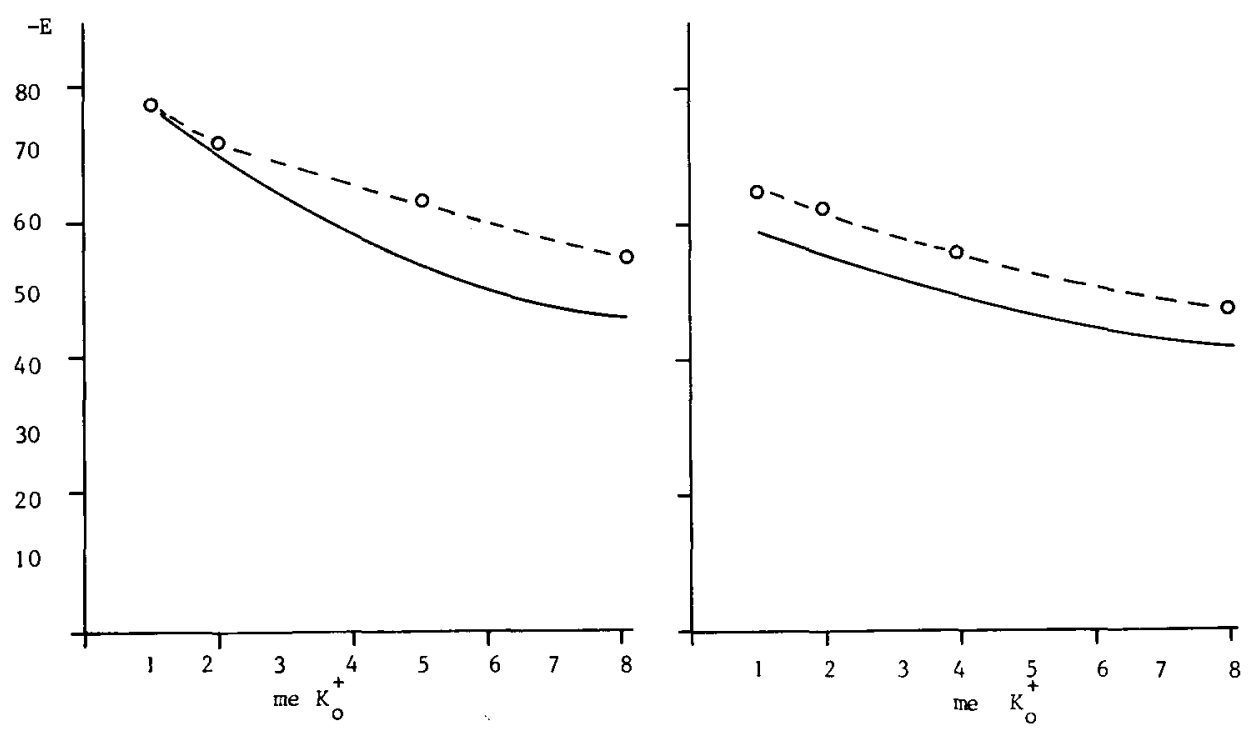

Fig. 2. Potentials in chloride solutions of mono- and divalent cations. 
In all cases where mixed solutions of $\mathrm{KCl}$ with $\mathrm{NaCl}, \mathrm{CaCl}_{2}$ and $\mathrm{MgCl}_{2}$ were used the trend of the potential drop shows close agreement with experimental values.

Additions of $\mathrm{CaCl}_{2}$ and $\mathrm{MgCl}_{2}$ to $\mathrm{KCl}$ slightly increased to potential above the theoretical potentials calculated according to the assumption above.

A similar effect was also reported by Laties et al. (1964). They proposed that this can be achieved either by having the permeability of $\mathrm{Ca}^{2+}$ very much smaller than that for chloride, or by $\mathrm{Ca}^{2}+$ so affecting the membrane as to reduce the permeability of outgoing $\mathrm{K}^{+}$or by a combination of both. In our suggested model with very low activities of $\mathrm{K}^{+}$and $\mathrm{Ca}^{2}+$ inside, another possibility is that $\mathrm{Ca}^{2+}$ and $\mathrm{Mg}^{2}+$ affects the rate of carrier uptake of $\mathrm{K}+$ which would mean an increase in the ratio of $\mathrm{UH} / \mathrm{UK}$. This would be in agreement with the enhancing effect of divalent cations on the uptake of monovalent cations.

There may also be other membrane potentials in the root, for instance between the plasmalemma and cytoplasma and again between tonoplast and vacuole etc., which are not accounted for in this model. Because of the rapid establishment of a new equilibrium potential after the root is transferred from one solution to another, we have assumed that the steady state concerned would be mainly associated with the AFS and the initial rapid adsorptive binding of ions. We may therefore conclude that the diffusion model for the root surface potential explains the variations observed in solutions of various salts and mixtures of salts as well as or even better than the variations of the Donnan system. It also describes a steady state condition and not an equilibrium as is the case with a Donnan system. The selective of the plant root for certain ionic constituents, even in the initial phase of the uptake process when this can be interpreted as some kind of metal chelate formation, can also satisfactorily be explained.

\section{References}

Barber, D. A. \& R. Russell, 1961. The relationship between metabolism and the 'exchangeability' of ions in plant tissues. J. exp. Bot. 12: 252-260.

Briggs, G. E. \& R. N. Robertson, 1957. Apparent free space. A Rev. Pl. Physiol. 8: 11-30.

Burström, H., 1963. Growth regulation by metals and chelates. Adv. Bot. Res. 1: 73-100. Preston Academic Press, London.

Chabarek, S. \& A. E. Martell, 1959. Organic sequestering agents. Wiley, New York.

Epstein, E. \& J. E. Leggett, 1954. The absorption of alkaline earth cations by barley roots: Kinetics and mechanism. Am. J. Bot. 41: 785-791.

Fried, M. \& H. Broeshart, 1967. The soil-plant system. Academic Press, New York.

Fried, M. \& J. C. Noggle, 1958. Multiple site uptake of individual cations as affected by hydrogen ions. Pl. Physiol. 33: 139-144.

Fried, M., J. C. Noggle \& C. E. Hagen, 1958. The relationship between adsorption and absorption of cations. Proc. Soil Sci. Soc. Am. 22: 495-499.

Grobler, J. H., 1959. Initial phase ion uptake by plant roots and the interpretation of root potentials. Ph. D. thesis, University of Amsterdam. Excelsior, The Hague.

Hodgin, A. L. \& B. Katz, 1949. The effect of sodium ions on the electrical activity of the gaint axon of the squid. J. Physiol. 108: 37-77.

Hope, A. B., 1953. Salt uptake by root tissue cytoplasm the relation between uptake and external concentration. Aust. J. biol. Sci. 6: 396-409.

Hope, A. B. \& P. G. Stevens, 1952. Electrical potential differences in bean roots and their relation to salt uptake. Aust. J. scient. Res. B 5: 335-343.

Kurella, G. A., 1961. Polyelectrolytic properties of protoplasm and the character of resting potentials. In: A. Kleinzeller \& A. Kotyk (Ed.), Membrane transport and metabolism. Academic Press, New York.

Laties, G. G., 1959. Active transport of sait into plant tissue. A. Rev. Pl. Physiol. 10: 87. 
Laties, G. G., J. R. MacDonald \& J. Dainty, 1964. Influence of the counterion on the adsorption iso. therm for chloride at low temperature. Pl. Physiol. 39: 254-262.

Lundegårdh, H., 1940. Investigations into the absorption and accumulation of inorganic ions. LantbrHögsk. Annlr 8: 233-404.

Lundegårdh, H., 1955. Mechanisms of absorption, transport, accumulation and secretion of ions. $A$. Rev. Pl. Physiol. 6: 1-24.

Petterson, S., 1966. Active and passive components of sulfate uptake in sunflower plants. Physiologia Pl. 19: 459-492.

Rains, D. W., W. E. Schmid \& E. Epstein, 1964. Absorption of cations by roots. Pl. Physiol. 39: $274-278$.

Schuffelen, A. C., 1954. Absorption of potassium by the plant. Potassium Symp. 1954: 169-181.

Schuffelen, A. C. \& G. H. Bolt, 1958. Ionic equilibrium in soils. Trans. int. Soc. Soil Sci.. IInd and IVth Comm. (Hamburg, 1958) 2: 132-146.

Schuffelen, A. C. \& F. F. R. Koenigs, 1962. Plant nutrients in soils of different genesis. Trans. int. Soc. Soil Sci. IVth \& Vth Comm. (New Zealand): 105-120.

Schuffelen, A. C. \& R. Loosjes, 1942. The influence of the ion acivity and the ion concentration in the medium on the absorption of cations by plants. Proc. Kon. Ned. Akad. Wet. 45: 944-952.

Schuffelen, A.C.\& R. Loosjes, 1946. The importance of the ion activity of the medium and the root potential for the cation absorption by the plant. Proc. Kon. Ned. Akad. Wet. 49: 80-86.

Skemyakin, M. M., V. K. Antonov, L. D. Bergelson, V. T. Ivanov, G. G. Malenkov, Yua Ovchinnikov \& A. M. Shkrob, 1969. Chemistry of membrane-affecting peptides, depsipeptides and depsides (structure-function relations). In: The molecular basis of membrane function. Prentice Hall.

Teorell, T., 1935. Diffusion effect on ionic distribution. I. Theoretical considerations. Proc. Natn. Acad. Sci. 21: 152-161.

Wailsel, Y., Ruth Neumann \& E. Yael, 1966. The nature of the pH effect on the uptake of rubidium by excided barley roots. Physiologia Pl. 19: 115-121.

Wallace, A., 1962. Chelate-metal-chelate binding of importance in soil-plant relationship. In: A. Wallace (Ed.), A decade of synthetic chelating agents in inorganic plant nutrition, p. 124-126. Edwards Bros. 